\title{
L-Dopa in Parkinsonism associated with cerebellar dysfunction (probable olivopontocerebellar degeneration)
}

\author{
HAROLD L. KLAWANS, JR. AND EARL ZEITLIN \\ From the Department of Neurology, Rush Presbyterian-St. Luke's Medical Center, Chicago, \\ Illinois 60612, USA
}

SUMmaRY Two patients with combined cerebellar and Parkinsonian features consistent with ${ }_{-}^{\infty}$ olivopontocerebellar degeneration were treated with long term oral L-dopa. Both patients showed. $\vec{\circ}$ improvement of the Parkinsonian symptoms but the cerebellar symptoms were unchanged. It is $\overrightarrow{\vec{\omega}}$ suggested that the Parkinsonian manifestations of this syndrome are related to loss of dopamineo in the striatum secondary to lesions of the substantia nigra. It is suggested that other patients with similar disorders should be given a trial with L-dopa.

Olivopontocerebellar degeneration was first defined by Déjerine and Thomas (1900). They described two patients who developed progressive cerebellar dysfunction. In both instances the onset was in middle age, beginning in the legs and later involving the arms. The post-mortem examination of the brains or these patients revealed atrophy of the cerebellar cortex, bulbar olives, and pontine gray matter with degeneration of the middle and inferior cerebellar peduncles. There was no evidence of sclerosis or inflammation. Déjerine and Thomas attributed the clinical picture of progressive cerebellar ataxia to the combined degenerative changes involving olives, cerebellum, and pons and gave the name olivopontocerebellar degeneration to this entity. Although subsequent patients have often had additional symptoms, progressive cerebellar ataxia and intention tremor remain the unifying clinical manifestations of this disease.

Déjerine and Thomas were unable to find any hereditary basis for this disease in the two patients they studied; however, there is now strong evidence that olivopontocerebellar degeneration is frequently familial. Sanger Brown (1892) had previously reported familial cerebellar degeneration with spinal cord involvement. Marie (1893) differentiated these cases from Friedreich's ataxia and felt that they were related to familial cerebellar atrophy. Marie had not been able to document the pathology in these cases. Déjerine and Thomas felt that Marie's ataxia was different from their concept of olivopontocerebellar degeneration. Marie had described a familial form of degeneration with onset betwee the ages of 20 to 30 , while they had described ${ }_{a}$ J sporadic form with onset at a later age. Since the original description of this disease, other inves $\overline{-1}-\Phi$ gators have described hereditary forms of olivg-

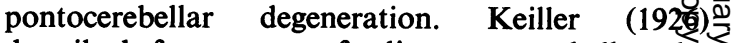
described four cases of olivopontocerebellar degeneration who had positive hereditary historie $\vec{\varphi}$ Three of these cases were verified on post-mortem.examination. Yang, Ling, and Chang (1938) have? reported the familial occurrence of this disease over five generations. Many other cases have been reported since then with and without pathological verification. Brown (1962) has concluded that many $\stackrel{\square}{\square}$ of the cases in the literature reported to be 'Marie's $\underset{\vec{F}}{\overrightarrow{7}}$ hereditary ataxia' are actually olivopontocerebellar 3 degeneration. It appears that, contrary to the original description, olivopontocerebellar degeneration is frequently hereditary and, in fact, is one of the spinocerebellar degenerations in which familial occurrence is common.

The current concept of the pathology of olivopontocerebellar degeneration has been outlined by Brown (1962) who describes diminution in the size of $\frac{3}{3}$ the pons, medulla, and cerebellum with extensive degeneration of the inferior olives and basal pontine $?$ nuclei with secondary gliosis. He also describes $\frac{D}{0}$ demyelinization of the cerebellar white matter with degeneration of Purkinje and ganglion cells. $N$ Critchley and Greenfield (1948) have described a 'tendency towards degeneration of other nuclei $N$ and fibre tracts subserving movement, but not directly 
connected with the cerebellum, e.g. dorsal columns and pyramidal tracts, substantia nigra, corpus luysii, and lenticular nucleus.' The findings of nigral and basal ganglia involvement in olivopontocerebellar degeneration, although not universally present, have been reported frequently. Scherer (1933) in his report of four instances of olivopontocerebellar degeneration noted regular changes in the substantia nigra and basal ganglia. These included marked depigmentation of the substantia nigra which he related to a 'local presenile aging process'. Lambie, Latham, and McDonald (1947) have reported significant involvement of the substantia nigra, caudate, putamen, and globus pallidus, as well as the regular features of olivopontocerebellar degeneration. Jellinger (1968) has reported a series of 15 cases of olivopontocerebellar degeneration in which there was frequent involvement of the substantia nigra. He described striatal degeneration including severe demyelinization of the putamen with complete loss of large neurones and dense gliosis associated with minor damage to the pallidum as well as involvement of the reticular zone of the substantia nigra.

From these studies of post-mortem material it appears that the substantia nigra and areas of the basal ganglia are frequently involved. Since alterations of the substantia nigra are felt to be the single most important lesion in the production of Parkinsonism (Greenfield and Bosanquet, 1953; Klawans, Ilahi, and Shenker, 1970), it would not be surprising if some patients with olivopontocerebellar degeneration had Parkinsonian features.

Extrapyramidal symptoms have been described in numerous patients. Déjerine and Thomas (1900) as well as Marie (1893) mentioned rigidity as one of the minor symptoms of the syndrome. Von Stauffenberg (1918) reported extrapyramidal symptoms in his case report of olivopontocerebellar degeneration. Scherer (1933) later recognized the relationship between Parkinsonism and nigral involvement in patients with olivopontocerebellar degeneration. He reported four patients who developed a combined syndrome of Parkinsonism (progressive rigidity, masked facies) and cerebellar dysfunction (severe difficulty in coordination). On post-mortem examination the findings were those of olivopontocerebellar degeneration with marked depigmentation of the substantia nigra as well as changes in the basal ganglia. Messing (1930) reported on a 62-yearold woman who had a 'classic case of Parkinson's Disease, although the signs of hypertonia and tremor were not striking'. The post-mortem examination revealed olivopontocerebellar degeneration. Lambie, Latham, and McDonald (1947) presented a similar case. Many other investigators have also recognized the clinical manifestations of Parkinsonism in olivopontocerebellar degeneration, both hereditary and sporadic types (Ley, 1924; Guillain, Mathieu, and Bertrand, 1926; Guillain, Thévenard, and Jonesco, 1928; Guillain and Thévenard, 1931).

The significance of the nigral involvement in olivopontocerebellar degeneration and of the clinical appearance of Parkinsonism in this disorder is supported by two other observations. Olivopontocerebellar degeneration was discovered coincidentally in patients who were studied because of progressive extrapyramidal symptoms. Adams, van Bogaert, and Vander Eecken (1964) have reviewed the four known instances of striato-nigral degeneration, a rare entity in which extrapyramidal signs are prominent. One of the patients was a 51-year-old woman with a negative family history who developed progressive rigidity, bradykinesia, masked facies, and rest tremor. Later she developed ataxia and intention tremor of the arms and legs before expiration. On post-mortem examination the findings were those of striatonigral degeneration plus olivopontocerebellar degeneration. Greenfield and Bosanquet (1953) have reviewed the brain-stem lesions in Parkinsonism. They related the specific aspects of nigral pathology to the categories of cases they reported, including 19 cases with idiopathic Parkinson's disease, 10 cases with Parkinsonism with a history of encephalitis between 1918 and 1924, and five cases with Parkinsonism of uncertain aetiology. The post-mortem examination of one of these diagnosed as Parkinsonism of uncertain aetiology revealed the findings of olivopontocerebellar degeneration with cell loss of the substantia nigra. This particular case had been reported earlier as an instance of olivopontocerebellar degeneration by Critchley and Greenfield (1948). Before death the patient had a progressive cerebellar ataxia of five years' duration and Parkinsonism for one year.

Olivopontocerebellar degeneration most often presents as a progressive cerebellar ataxia. However, it is clear that the substantia nigra is frequently involved in this disease. This involvement manifests itself as Parkinsonism. The Parkinsonian manifestations can be mild or can dominate the clinical picture. The combined occurrence of Parkinsonism and cerebellar symptoms raises the question as to whether the mixed syndrome is the manifestation of a single pathological entity (olivopontocerebellar degeneration including nigral involvement) or the coincidental occurrence of two separate entities. The fact that progressive Parkinsonism with cerebellar dysfunction occurs as a hereditary entity suggests that a single pathological entity is responsible for the combined syndrome. 
Recent work with L-dopa has created greater interest in Parkinsonism and in the treatment of patients with possibly related syndromes. There have been no reported cases of olivopontocerebellar degeneration treated with L-dopa. This paper will present the results of L-dopa treatment in two patients who had a combined syndrome of Parkinsonism and cerebellar dysfunction, compatible with olivopontocerebellar degeneration.

\section{CASE 1}

A 55-year-old white female was in good health until age 46 when she noted the onset of tremor in her right leg. At that time she was told that she had Parkinsonism. The tremor was relatively non-progressive until the age of 53, but since then she has had progressive tremor of both upper extremities and difficulty in walking. The tremor was characterized by the patient as being present both at rest and on intention. She felt that it was more marked in the right than in the left upper extremity, but was equal in the lower extremities.

In addition, the patient has noticed a problem with walking and with balance. This began with difficulty in walking in high heels but for the last two years her gait difficulty has been increasing. She complains of progressive difficulty with balance, spontaneous propulsion and retropulsion, as well as an inability to adjust to any force while standing. In recent months the patient has tended to fall if unsupported while standing or sitting. The patient was unable to stand without support and had difficulty in feeding herself or dressing herself. There was no history of intellectual impairment. She was on trihexyphenidyl $2 \mathrm{mg}$ three times a day and diphenhydramine $25 \mathrm{mg}$ three times a day.

There is a history of similar disability in the patient's family over at least three generations. The patient's maternal grandfather was said to have had progressive tremor and stiffness beginning in late adult life, while her mother had severe progressive difficulty with balance as well as tremor beginning after she was 60 . Neither the patient's father, maternal grandfather, or paternal grandparents had any similar problem. Three of the patient's mother's five siblings had similar problems. Two had tremors and gait difficulty, while one had slowness in walking and stiffness without noticeable tremor. The patient's only sibling, a brother, has progressive balance and gait difficulty as well as tremor and stiffness. This began when he was about 50 . The patient has no children. She does not know if any cousins have similar problems but all of these are at least seven years younger than the patient. None of other family members has been examined by us.

General physical examination revealed no significant abnormalities. The patient had a normal mental status. Optic discs were normal and cranial nerves were intact except for a moderately masked facies. The patient had a gross rest tremor of both upper extremities. It was more prominent in the right arm than the left arm and was more pronounced distally. The tremor decreased slightly on the initiation of willed movement but increased greatly on intention. There was marked intention tremor on finger pursuit or on finger-to-nose movements. There was a rest tremor of the lower extremities of equalo intensity. The patient had gross titubation and truncal ataxia with inability to stand or sit without tending to fall. Her stance was wide based even with support. She was ${ }_{0}$ unable to tolerate a narrow base. There was no response on the part of the patient to a backward push on the - . sternum (absence of postural reflex). Movements were $\stackrel{乛}{\rightleftharpoons}$ slow and there was slowness in both initiating and carry-.. ing out gross movements such as getting out of a chair. Finger dexterity was slowed bilaterally as were all rapid $\stackrel{\mathcal{F}}{+}$ alternating movements. Glabellar, palmomental, and $\bar{C}$ Babinski reflexes were elicited bilaterally but snout or $\underline{\underline{\underline{\sigma}}}$ suck reflexes could not be obtained. Deep tendon $\frac{\bar{s}}{\sqrt{2}}$ reflexes were active and equal. There was no weakness or $\stackrel{\mathbb{Q}}{\varrho}$ atrophy and sensation was within normal limits.

The patient was admitted to the hospital and $a^{œ}$ pneumoencephalogram was done which was normal. The $\vec{\circ}$ spinal fluid contained no cells. The protein content was $37 \mathrm{mg} / 100 \mathrm{ml}$. The homovanillic acid level was $11 \vec{\omega}$ $\mathrm{ng} / \mathrm{ml}$. The patient was continued on her regular medications and then started on L-dopa as outlined by Klawans and Garvin (1969). She reached a maintenance? dosage of $\mathbf{4} \mathrm{g}$ daily and showed progressive improvement $\omega_{\perp}$ over several months. After one month on L-dopa thepatient was able to sit and stand without supporf. $\vec{A}$ Detailed evaluation after six months of L-dopa thera revealed that she walked with a wide base and was still 5 unable to tolerate a narrow base. Her postural reflexes were normal and she had not fallen in several montts. T) She was now walking both inside the house and outside by herself. She had not done the latter for over one year? before taking L-dopa. Her face now demonstrated onfy minimal hypomimia. The rest tremor was marked $\vec{F}$ improved but the titubation and intention tremor were unchanged. The Babinski and palmomental reflexes. persisted but the glabellar reflex could no longer be elicited. There was no slowness apparent on gross movements although fine movements remained slow.

COMMENT It was our initial impression that this $\stackrel{0}{\circ}$ patient had a familial degenerative disease with both $\stackrel{\varrho}{\Rightarrow}$ Parkinsonian and cerebellar features. Her major $\overrightarrow{\vec{O}}$ disability was related to her marked difficulty with balance. While some of this was felt to be related to her cerebellar deficit, it was felt that the loss of postural reflexes might contribute to this problem. She was placed on L-dopa and regained normal? postural reflexes and marked improvement in gait and balance. The Parkinsonian features improved dramatically on L-dopa, while the cerebellar deficits remained unchanged.

CASE 2

A 64-year-old white male was in good health until aged 60 when he noted progressive slowness and difficulty in $\mathrm{N}$ initiating and carrying out movements. This involved $\mathrm{N}$ all four extremities and was associated with a feeling of $\mathrm{N}$ stiffness in his neck, arms, and legs. Over the past two $\omega$ 
years he has noted difficulty in balance and has felt unsteady while walking. He also has noted tremor of both hands. The tremor was present at rest as well as during activities such as eating. Over the last year he developed progressive speech difficulty. He had been on trihexyphenidyl $2 \mathrm{mg}$ three times a day and was recently placed on amantadine hydrochloride without any apparent improvement. The patient stated that his father had had progressive stiffness and walking difficulty beginning sometime late in life but he was unaware of any other family members with similar difficulty.

General physical examination was unremarkable. On neurological evaluation the patient was noted to have a severely masked facies. The cranial nerves were otherwise normal. His speech was slow and monotonous but his mental status was normal. The gait was broad based with decreased associated movements bilaterally. The patient was unable to stand. Pushing on his sternum produced retropulsion without recovery. There was a 4 to $5 \mathrm{c} / \mathrm{s}$ rest tremor of both hands. This improved on the initiation of movement but a definite intention tremor was present on finger pursuit and finger-to-nose movements. Definite cogwheel rigidity was present in the neck and all four extremities. Finger dexterity was slowed bilaterally, while there was slowness in initiating and carrying out gross movements. Babinski and palmomental reflexes were elicited bilaterally as was a glabellar reflex. Suck and snout reflexes could not be elicited. The deep tendon reflexes were equal bilaterally. There was no atrophy and sensation was within normal limits.

The patient was admitted to the hospital. He was continued on trihexyphenidyl, but amantadine hydrochloride was discontinued. The spinal fluid contained no cells and spinal fluid protein was $42 \mathrm{mg} / 100 \mathrm{ml}$. Spinal fluid homovanillic acid level was $7 \mathrm{ng} / \mathrm{ml}$. Treatment of the patient was begun with L-dopa as described above and maintained on $4 \mathrm{~g}$ per day. The patient improved progressively on L-dopa. His difficulty in initiating and carrying out movements decreased. He was able to get up from a chair rapidly and to walk without significant slowness. After six months of L-dopa therapy the patient's condition was re-evaluated. The rest tremor was absent but the intention tremor was unchanged. The patient had increased facial expression. His gait was improved and he had better associated movements. The base was still wide but he had no difficulty in turning. He was able to walk several miles a day, whereas previously he could not walk more than one to two blocks. He could now easily get out of a chair unaided. Retropulsion was no longer present. Rigidity was still present but less marked.

COMMENT This patient showed a clinical picture with both Parkinsonian and cerebellar features. Long term oral L-dopa therapy resulted in amelioration of many of the Parkinsonian features without changing the cerebellar symptoms. This significantly modified his disability.

\section{DISCUSSION}

The most significant lesion in Parkinsonism is degeneration of the cell bodies of the substantia nigra (Forno, 1966; Greenfield and Bosanquet, 1953). This cell loss results in degeneration of the nigrostriatal pathway (Andén, Carlsson, Dahlström, Fuxe, Hillarp, and Larsson, 1964; Andén, Dahlström, Fuxe, and Larsson, 1965) with a subsequent loss of the normal dopaminergic input to the striatum (Hornykiewicz, 1966). It has been suggested that this loss of dopaminergic influence on the striatal neurones is the most significant factor in the production of all of the symptoms of Parkinsonism (Klawans, Ilahi, and Shenker, 1970). L-dopa (L,3,4 dihydroxyphenylalanine) is the normal precursor of dopamine. It is decarboxylated to form dopamine by dopa decarboxylase. Dopamine is said to be a neurotransmitter and is thought to inhibit the neurones of the striatum (MacLennan and York, 1967). It has been suggested that the effectiveness of L-dopa in Parkinsonism derives from a reinstitution of dopamine inhibition of the striatal neurones (Barbeau, 1962; Hornykiewicz, 1966). This is said to be a result of the action of dopamine at striatal dopamine receptors. If this is true, L-dopa would not influence symptoms which are not related to decreased or altered dopaminergic influence on striatal neurones (Klawans, 1968). There are, however, no detailed reports on the results of long-term L-dopa therapy in patients with symptoms unrelated to basal ganglia dysfunction. The results of the use of L-dopa in the two patients presented here support the concept that L-dopa acts specifically on symptoms related to lesions of the dopaminergic system.

Both patients had combined cerebellar and Parkinsonian features. Each also had bilateral Babinski signs indicating coexisting pyramidal tract involvement. Both gave a history of other family members with similar involvement. In the first patient there is a history of involvement in many members over three generations, while in the second patient there is only a history of similar disease in the father. As outlined above, it was felt that the patients had olivopontocerebellar degeneration. The occurrence of reportedly similar problems in other family members is felt to support this diagnosis. The diagnosis of olivopontocerebellar degeneration implies that there is involvement of the nigrostriatal neurones of the substantia nigra as part of the disease process. This involvement can be identical with the alterations seen in Parkinsonism (Greenfield and Bosanquet, 1953). The assumption that these two patients had lesions of the substantia nigra is of practical significance, since the symptoms resulting from such a lesion are usually improved by L-dopa.

A definite diagnosis of olivopontocerebellar degeneration can only be made on the basis of necropsy material. However, from a practical stand- 
point, the degree of involvement of the nigrostriatal system can be estimated by measuring spinal fluid homovanillic acid. Homovanillic acid is the major catabolic product of dopamine. Its concentration within the cerebrospinal fluid is a reflection of dopamine metabolism within the central nervous system (Bartholini, Pletscher, and Tissot, 1966; Pletscher, Bartholini, and Tissot, 1967). Spinal fluid homovanillic acid levels are decreased in Parkinsonism (Bernheimer, Birkmayer, and Hornykiewicz, 1966). This is felt to reflect the decreased dopamine concentration found in the striatum and substantia nigra of these patients. Spinal fluid homovanillic acids increase greatly after L-dopa therapy and this increase is felt to reffect increased utilization of dopamine within the central nervous system (Weiner, Harrison, and Klawans, 1969).

Spinal fluid homovanillic acid levels were estimated in both patients before the institution of L-dopa. It was significantly decreased in both patients. The range in normal subjects and patients without Parkinsonism has been shown to range from 30 to $100 \mathrm{ng} / \mathrm{ml}$. (Andén, Roos, and Werdinius, 1963). Barolin and Hornykiewicz (1967) consider $35 \mathrm{ng} / \mathrm{ml}$. to be the lower limit of normal. The spinal fluid homovanillic acid level in case 1 was $11 \mathrm{ng} / \mathrm{ml}$., while in case 2 it was $7 \mathrm{ng} / \mathrm{ml}$. These decreased values were interpreted as suggesting that there was decreased dopamine utilization in both patients as a reflection of involvement of the nigrostriatal dopaminergic neuronal system. While decreased levels of homovanillic acid have been reported in conditions other than Parkinsonism (Barolin and Hornykiewicz, 1967), levels as low as these reported here have been seen only in Parkinsonism or meningoencephalitis. Neither of the patients reported had cells in the spinal fluid or other evidence of inflammatory disease.

Lesions of the striatum itself and of the pallidum which have been reported in olivopontocerebellar degeneration could perhaps contribute to the extrapyramidal features in these patients. If L-dopa acts as dopamine at the striatal dopamine receptors then symptoms due to striatal or pallidal lesions might not improve on L-dopa (Klawans and Erlich, 1969; Klawans, Ilahi, and Shenker, 1970).

Lesions of the striatum or pallidum would probably not account for decreased levels of spinal fluid homovanillic acid, since the dopamire metabolism is controlled by the cells of the substantia nigra not those of the striatum or pallidum (Andén et al., 1964, 1965). It was felt that the depressed levels of homovanillic acid in these two patients suggested that lesions of the substantia nigra were significant and that L-dopa might be of some use. While this conclusion was obvious in the second patient whose clinical condition was dominated by the symptoms of Parkinsonism, it was not as obvious in case 1 in whom ataxia appeared to be the dominantw problem.

Both patients showed definite amelioration of theiro Parkinsonian symptoms from long-term oral L-dopas therapy. This is consistent with attributing the? Parkinsonian manifestations to lesions of the substantia nigra and subsequent dopaminergic denervation of the striatum. This supports the view $\overrightarrow{\vec{F}}$ of Scherer (1933), who attributed the Parkinsonianfeatures of olivopontocerebellar degeneration to lesions of the substantia nigra.

While both patients improved on L-dopa, the improvement in case 1 is of greater interest. This patient was totally disabled because of her inabilityes to sit or stand without support. She had titubation $\vec{\circ}$ and ataxia as well as absent postural reflexes. It wasdifficult to tell to what degree cerebellar ataxia and $\vec{\omega}$ Parkinsonian loss of postural reflexes were con $\frac{\rho}{5}$ tributing to her inability to stand. Because of the frequent improvement of postural reflexes by L-dopa, as initially pointed out by Klawans and ${ }^{+}$ Erlich (1969), the patient was placed on L-dop $\overrightarrow{.}$ Her improvement was dramatic and, although she remains ataxic, she is now able to care for hersef 5 and carry on an active life.

The experience with L-dopa in this patient sugge T that, in patients with combined cerebellar and Parkinsonian syndromes, a major part of the ga्यू disability may be related to loss of postural reflexes. Since this frequently responds to long-term ota L-dopa therapy such patients should be given a trial. of this drug.

The cerebellar symptoms of ataxia, intentions tremor, and titubation were unaltered in these two patients. Since some patients with Parkinsonism have shown initial improvement on L-dopa only $\underset{\complement}{\mathbb{Q}}$ after three to six months of oral therapy (Godwin- $\overrightarrow{\vec{P}}$ Austen, Tomlinson, Frears, and Kok, 1969), it $\frac{}{3}$ should be noted that both these patients have been on L-dopa for over six months without any change in cerebellar symptoms. The clear differentiation in response of the Parkinsonism and cerebellar symptoms suggests that the pathogenesis of the two types: of symptoms is different, even though the aetiological 3 basis is probably identical. The cellular alterations

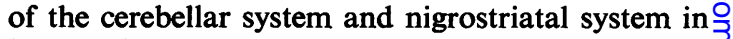
both patients are hereditary. While it is possible that the basic genetic defect may differ from family to 3 family, it is most probable that the primary neuronal? defect in any one family is the same in all the involved neurones. The same genetic lesion involves $N$ the pigmented cells of the substantia nigra as the cells of the cerebellum and perhaps of the olives and 0 pons. Only the defect related to the lesion of the $\omega$ 
substantia nigra is reversible by L-dopa. This is because the lesions of the substantia nigra result in a loss of dopamine input into the striatum which can be reversed by L-dopa.

The L-dopa used in this study was generously supplied by the Norwich Pharmacal Company, Norwich, New York. This study was partially supported by a grant from the United Parkinson Foundation, Chicago, Illinois (President: Edgar N. Greenbaum, Jr.).

\section{REFERENCES}

Adams, R. D., van Bogaert, L., and Vander Eecken, H. (1964). Striato-nigral degeneration. J. Neuropath. exp. Neurol., 23, 584-608.

Andén, N. E., Carlsson, A., Dahlström, A., Fuxe, K., Hillarp, N. A., and Larsson, K. (1964). Demonstration and mapping out of nigro-neostriatal dopamine neurons. Life Sci., 3, 523-530.

Andén, N. E., Dahlström, A., Fuxe, K., and Larsson, K. (1965). Further evidence for the presence of nigroneostriatal dopamine neurons in the rat. Amer. J. Anat., 116, 329-333.

Andén, N. E., Roos, B. E., and Werdinius, B. (1963). On the occurrence of homovanillic acid in brain and cerebrospinal fluid and its determination by a fluorometric method. Life Sci., 2, 448-458.

Barbeau, A. (1962). The pathogenesis of Parkinson's disease: a new hypothesis. Canad. med. Ass. J., 87, 802-807.

Barolin, G. S., and Hornykiewicz, O. (1967). Diagnostic significance of homovanillic acid in the cerebrospinal fluid. Wien. klin. Wschr., 79, 815-818.

Bartholini, G., Pletscher, A., and Tissot, R. (1966). On the origin of homovanillic acid in the cerebrospinal fluid. Experientia (Basel), 22, 609-610.

Bernheimer, H., Birkmayer, W., and Hornykiewicz, O. (1966). Homovanillic acid in cerebrospinal fluid. Wien. klin. Wschr., 78, 417-419.

Brown, J. R. (1962). Diseases of the cerebellum. In Clinical Neurology, 2nd edn., pp. 1406-1455. Edited by A. B. Baker. Hoeber-Harper: New York.

Brown, S. (1892). On hereditary ataxy, with a series of twentyone cases. Brain, 15, 250-268.

Critchley, M., and Greenfield, J. G. (1948). Olivo-pontocerebellar atrophy. Brain, 71, 343-364.

Déjerine, L., and Thomas, A. (1900). L'atrophie olivoponto-cérébelleuse. Nouv. Iconogr. Salpêt., 13, 330-370.

Forno, L. S. (1966). Pathology of parkinsonism. A preliminary report of 24 cases. J. Neurosurg., 24, 266-271.

Godwin-Austen, R. B., Tomlinson, E. B., Frears, C. C., and Kok, H. W. L. (1969). Effects of L-dopa in Parkinson's disease. Lancet, 2, 165-168.

Greenfield, J. G., and Bosanquet, F. D. (1953). The brainstem lesions in parkinsonism. J. Neurol. Neurosurg. Psychiat., 16, 213-226.

Guillain, G. P., Mathieu, P., and Bertrand, I. (1926). Étude anatomo-clinique sur deux cas d'atrophie olivo-pontocérébelleuse avec rigidité. Ann. Méd., 20, 417-459.
Guillain, G., and Thévenard, A. (1931). Sur un syndrome cérébelleux précéde d'un état hypertonique de type Parkinsonien. Rev. neurol., 2, 130.

Guillain, G., Thévenard, A., and Jonesco, D. (1928). Un cas de syndrome cérébelleux du type de l'atrophie olivoponto-cérébelleuse avec développement progressif d'un état hypertonique. Rev. neurol., 2, 890-895.

Hornykiewicz, O. (1966). Dopamine (3-hydroxytyramine) and brain function. Pharm. Rev., 18, 925-964.

Jellinger, K. (1968). Degenerations and exogenous lesions of the pallidum and striatum. In Handbook of Clinical Neurology, vol. 6, pp. 632-693. Edited by P. J. Vinken and G. W. Bruyn. North-Holland Publishing Co.: Amsterdam.

Keiller, W. (1926). Four cases of olivo-ponto-cerebellar atrophy giving a history of heredity with three autopsies. Sth. med.J. (Bgham, Ala.), 19, 518-522.

Klawans, H. L., jun. (1968). The pharmacology of parkinsonism. Dis. nerv. Syst., 29, 805-816.

Klawans, H. L., jun., and Erlich, M. (1969). L-Dopa and the negative symptoms of parkinsonism. J. Neurol. Neurosurg. Psychiat., 32, 460-461.

Klawans, H. L., and Garvin, J. S. (1969). Preliminary observations on the treatment of parkinsonism with L-dopa; a study of 105 patients. Dis. nerv. Syst., 30, 737-746.

Klawans, H. L., Ilahi, M. M., and Shenker, D. (1970). Theoretic implications of the use of $\mathrm{L}$-dopa in parkinsonism. Acta neurol. scand. In press.

Lambie, C. G., Latham, O., and McDonald, G. L. (1947). Olivo-ponto-cerebellar atrophy. Marie's ataxia. Med. J. Aust., 2, 626-632.

Ley, R. A. (1924). Forme atypique d'atrophie cérébelleuse ayant évolué en syndrome rigide. Arch. int. Méd. exp., 1, 277-299.

Marie, P. (1893). Sur l'hérédo-ataxie cérébelleuse. Sem. méd. (Paris), 13, 444-447.

McLennan, H., and York, D. H. (1967). The action of dopamine on neurons of the caudate nucleus. J. Physiol. (Lond.), 189, 393-402.

Messing, Z. (1930). Atrophie olivo-ponto-cérébelleuse dans un cas de maladie de Parkinson. Rev. neurol., 1, 498-499.

Pletscher, A., Bartholini, G., and Tissot, R. (1967). Metabolic fate of $\mathrm{L}-\left[{ }^{14} \mathrm{C}\right]$ DOPA in cerebrospinal fluid and blood plasma of humans. Brain Res., 4, 106-109.

Scherer, H. J. (1933). Extrapyramidale Störungen bei der Olivopontocerebellarer Atrophie. Ein Beitrag zum Problem des lokalen vorzeitigen Alterns. Zbl. ges. Neurol. Psychiat., 145, 406-419.

Von Stauffenberg (1918). Zur Kenntnis des extrapyramidalen motorischen Systems und Mitteilung eines Falles von sogenannter 'Atrophie olivo-ponto-cérébelleuse'. Z $\mathrm{bl}$. ges. Neurol. Psychiat., 39, 1-55.

Weiner, W., Harrison, W., and Klawans. H. (1969). L-dopa and cerebrospinal fluid homovanillic acid in Parkinsonism. Life Sci., 8, 971-976.

Yang, C., Ling, M., and Chang, S. (1938). Hereditary ataxia ; familial occurrence in 5 generations. China med. J., 53, 161-168. 